\title{
ACTIVIDADES DEL CENTRO DE ESTUDIOS IBERO-AMERICANOS DE LA UNIVERSIDAD CAROLINA, 2010-2015
}

En los años correspondientes, el Centro de Estudios Ibero-Americanos de la Universidad Carolina de Praga (sede: Hybernská 3, Praha 1; dirección postal: nám. Jana Palacha 2, 11638 Praha 1, República Checa; dirección electrónica: ibero@ff.cuni .cz), un lugar de trabajo interdisciplinario dedicado a la investigación y la docencia en el área mencionada, continuó desempeñándose como departamento independiente en el marco de la Facultad de Filosofía, con la finalidad de ofrecer cursos de $2^{\circ}$ ciclo en iberoamericanística a los estudiantes que ya hayan alcanzado el grado de bachiller (Bc.) en sus carreras y quisieran recibirse en estudios iberoamericanos (Mgr.), y cursos de especialización en Historia de América Latina - Iberoamericanística a los estudiantes de la carrera de Historia Universal que se realiza en el Instituto de Historia Universal. Otros estudiantes -particularmente de Filología Románica, Filología Inglesa-Americanística, Traducción e Interpretación, Etnología, etc.- pueden cursar las asignaturas como optativas. El Centro ofrece también estudios de doctorado en el programa Ciencias Históricas - Iberoamericanística.

De la dirección del Centro de Estudios Ibero-Americanos está encargado el Prof. Dr. Josef Opatrný, CSc. Forma parte del cuerpo docente la Dra. Simona Binková, CSc., que sigue desempeñándose como vicedirectora del Centro, y la Doc. Mgr. Markéta Křížová, PhD., que, además de secretaria científica se encarga de coordinar los asuntos de estudio y de relaciones exteriores (programa de Erasmus y otros). En el dictado de los cursos participaron los profesores de la Facultad de Filosofía Prof. Dr. Vladimír Nálevka, CSc., del Instituto de Historia Universal (fallecido en 2010: ver su necrología en este volumen), Prof. Dra. Anna Housková, CSc., y Dra. Anna Mištinová, PhD., ambas del Instituto de Estudios Románicos, y como colaboradores externos Prof. Dr. Bohumír Janský, CSc. y Doc. RNDr. Eva Janská, Ph.D., ambos de la Facultad de Ciencias Naturales de la Universidad Carolina.
La Dra. Simona Binková, CSc., a lo largo de más de tres lustros, desempeñaba también el cargo de jefa de redacción del anuario Ibero-Americana Pragensia (de 1993 a 2015, vols. 27 a 44). En el cargo de revisar las traducciones al español, al Lic. Luis Pérez-Cuesta Romero (que se había retirado) le sustituyó el Dr. Juan A. Sánchez del Departamento de Estudios Románicos. El Dr. Sigfrido Vázquez Cienfuegos, doctor en Historia por la Universidad de Sevilla, se incorporó primero como becario del Ministerio de Educación, Cultura y Deporte y desde 2015 como profesor-investigador contratado. El mismo se encarga desde su incorporación también de la supervisión de los textos de la serie de Ibero-Americana Pragensia Supplementum que vive un aumento cuantitativo considerable. En los últimos volúmenes de Ibero-Americana Pragensia coparticiparon en la revisión de textos portugueses sin fines de lucro el Director del Instituto Camões en Praga Joaquim Coelho Ramos, Sérgio P. Oliveira adjunto a la misma institución, la Dra. Marie Havlíková, traductora y profesora de las literaturas lusófonas en varias Universidades de la República Checa (Praga, Plzeň, Brno y Olomouc) y Frederico Guilherme Monturil Rêgo, estudiante de posgrado de iberoamericanística en el mismo Centro. También ha habido cambios en la organización de la biblioteca del Centro. Se ha retirado la Dra. Zdeňka Vorlová sustituida por nuevas fuerzas de biblioteconomía.

En cuanto a la participación en asuntos académicos a nivel de la Facultad, J. Opatrný ya desde antes y durante todo ese periodo ha formado parte del Consejo Científico. A partir del año 2014 fue escogido por la Decana para representar el programa de estudios en Historia en el Consejo de Gerentes recién establecido. S. Binková en tres periodos sucesivos (de 2008 a 2014) fue miembro del Senado Académico, formando en su segundo periodo parte de la comisión de bibliotecas. M. Křížová, desde enero de 2012, es miembro del consejo de la sección Humanidades de la Agencia Grant de la Universidad Carolina. De 2012 a 2014 
se desempeñó también en la comisión de relaciones exteriores adjunta al Senado Académico de la Facultad.

\section{Las tareas básicas del Centro: enseñanza}

Se siguió la labor docente, llevada a cabo en dos áreas:

$1^{\circ}$ - Desarrollando el curso de iberoamericanística, que se compone de las siguientes asignaturas: Culturas nativas y Conquista (M. Křrižová), Historia Colonial (S. Binková), Historia del siglo XIX (J. Opatrný), Historia del siglo XX (V. Nálevka, continuado por Josef Opatrný), Fuentes para el estudio de la Historia de Iberoamérica (S. Binková), Historiografía de América Latina (M. Křížová), Geografía (M. Janský y E. Janská), Literaturas Hispanoamericanas (A. Housková), El Español de América (A. Mištinová). Para los estudiantes no hispanistas se proporcionan cursos de Introducción al estudio de Historia y Cultura de América Latina (J. Opatrný) y de Español para principiantes (S. Binková). Todo este curso está concebido como curso de $2^{\circ}$ ciclo y de especialización en Historia de América Latina - Iberoamericanística; sin embargo, sus clases también están abiertas -como optativas- a estudiantes de otras carreras de la Facultad de Filosofía. Además, se prepararon diferentes cursos optativos: Lectura de textos referentes a las relaciones checo-luso-brasileñas (S. Binková), Música latinoamericana (Z. Straková), Cultura brasileira (F. G. Monturil Rêgo), Historia del Arte de América Latina (M. Brenišínová), los tres últimos temas llevados a cabo por estudiantes de doctorado.

$2^{\circ}$ - Dando clases de Historia y Cultura Españolas e Hispanoamericanas en el Instituto de Estudios Románicos y en el de Traductología - Español (J. Opatrný), y de Historia de Portugal y Brasil en el Instituto de Estudios Románicos (S. Binková). Además, se proporciona también el curso de Historia de los Estados Unidos para los estudiantes del Instituto de Traductología - Inglés (J. Opatrný). Esas clases forman parte del programa de grado de los respectivos Institutos. Además, se impartieron clases para los estudiantes del programa Erasmus en el Instituto de Historia Universal (M. Kř́ížová). Los profesores del Centro participaron también como miembros de comisiones de estudios de grado y doctorales en la Facultad de Filosofía y en la Facultad de Ciencias Sociales de la UC y en la Escuela Superior de Economía (VŠE).

En el Centro, entre 2010 y 2015, fueron defendidas en total 59 tesis de $2^{\circ}$ ciclo de estudios (máster): 10 en el curso académico 2009/2010; 9 en 2010/2011; 3 en 2011/2012; 10 en 2012/2013; 19 en 2013/2014; 8 en 2014/2015. Además, el profesorado participó en orientar, o en oponer las tesis -tanto del $1^{\text {ero }}$, como $2^{\circ}$ ciclo- en otros departamentos e institutos de la Universidad Carolina, eventualmente de otras universidades del país.

En el Centro se imparte también un curso de posgrado con especialización en estudios iberoamericanos. Fueron defendidas 15 disertaciones doctorales: en 2010/11, Miloš Ondřej Kosina (El desarrollo político de la República española de 1931 a 1939, en checo - JO), Sylvie Květinová Voláková (Material culture as a vehicle of social-political organization: Chimú pottery - MK), Vendula Vlková Hingarová (La administración del lenguaje del náhuatl en México - FV), Hana Vondráková Bortlová (Checoslovaquia y Cuba en los años 1959 a 1962, en checo - JO); en 2011/2012, Ximena del Carmen Alfaro Negrete (Las dictaduras latinoamericanas como fuente de inspiración literaria: narrativa del siglo XX - JO), Michala Bernkopfová (Posibilidades para el mantenimiento de la identidad cultural de los nahuas de la Sierra Nororiental de Puebla: El caso de la Unión de Cooperativas Tosepan Titataniske - MK), Lukáš Perutka (Checoslovaquia, Guatemala y México en el período de la Revolución Guatemalteca - JO), Magdalena Villatoro Sládková (La Familia: The Analysis of Family in Selected Works of Mexican American Literature - MK); en 2012/2013, Radek Buben (La deconsolidación de la democracia en Venezuela: corrosión del sistema de partidos, neo-populismo y la repolitización de las Fuerzas Armadas - JO), Armando Laureano Perryman Figueroa (Visión de José Martí sobre Europa, a través del estudio de sus "Escenas europeas" - JO); en 2013/14, Eva Daříčková (El Ejército argentino como factor económico - JO), Jiří Frýda (Threats to Economic Interests of the EU in Central and South America - JO), Michal Zourek (Checoslovaquia y el Cono Sur 1945-1989 - JO); en 2014/15, Petr Hertel (Los intentos de España por recuperar o fortalecer sus posiciones internacionales en los años sesenta del siglo XIX - JO), Lucia Majlátová (Relaciones entre Checoslovaquia, México y América Central 1945-1989 - JO), significando las siglas a los orientadores Josef Opatrný (11), Markéta Křížová (3) y František Vrhel, éste último del Departamento de Etnología (1).

Algunas de las disertaciones fueron publicadas como: H. Bortlová, Československo a Kuba 
$v$ letech 1959-1962 (Checoslovaquia y Cuba en los años 1959-1962, FF UK, Praha 2011); L. Perutka, Checoslovaquia, Guatemala y México en el período de la revolución guatemalteca (=Ibero-Americana Pragensia, Supplementum 30, Vydavatelství Karolinum, Praha 2013); M. Bernkopfová, La identidad cultural de los nahuas de la Sierra Nororiental de Puebla y la influencia de la Unión de Cooperativas Tosepan (=Ibero-Americana Pragensia, Supplementum 34, Vydavatelství Karolinum, Praha 2013); M. Zourek, Checoslovaquia y el Cono Sur 1945-1989. Relaciones políticas, económicas y culturales durante la Guerra Fría (=Ibero-Americana Pragensia, Supplementum 39, Vydavatelství Karolinum, Praha 2014).

\section{Seminario Iberoamericanista}

El Seminario Iberoamericanista del Centro de Estudios Ibero-Americanos se efectúa cada martes del semestre corriente, a las 16 horas, invariablemente desde los años 60 del siglo XX cuando fue establecido. Surgió como plataforma de reunión de académicos, estudiantes y egresados, personas cercanas a la problemática del mundo hispano-luso-americano, para convertirse en los años 90 en un seminario regular acreditado en la nueva disciplina de iberoamericanística estudiada a nivel de máster, materia obligatoria para los estudiantes que presentan y discuten aquí sus tesis. Sin embargo, este seminario conserva también su carácter y razón original: ser un lugar de acogida de profesores visitantes y espacio abierto para el intercambio de opiniones.

Por lo general, cada semestre se efectúa un promedio de 12 a 14 seminarios. Por eso, para el largo lapso de 2010 a 2015 es imposible marcar a todos los participantes, expondremos sobre todo a los conferenciantes extranjeros.

En 2010, presentaron sus temas de investigación: Andrés Lema-Hincapié (University of Colorado, Denver); Albert Manke (Universität zu Köln); Mayra Beers (FIU College of Business, Miami, Florida) y Sherry Johnson (Florida International University); Jiří Černík (Arlington, VA); Miguel Ángel Flores (Universidad Autónoma Metropolitana, campus Azcapotzalco, Ciudad de México).

En 2011, el Centro disfrutó de la presencia de Antonio Sáez-Arance (Universität zu Köln); Magdalena Śniadecka-Kotarska (Universidad de Varsovia y Universidad de Lodz, Polonia); Ramón Carreño, Cónsul de la República Dominicana, quien en nombre del Ministro de Cultura entregó una donación de libros al Centro de Estudios Ibero-Americanos de la Universidad Carolina; Fernando Villagómez Porras (CESLA Varsovia); Jiří Černík (Arlington, VA); Dorleta Apaloaza Llorente (Universidad del País Vasco); Josefina Zoraida Vázquez Vera (Investigadora de Excelencia, México); Aurelio de los Reyes García Rojas (UNAM, México); Armando Curbelo Fuentes (Las Palmas de Gran Canaria); Zora Rohoušová (Universidad Autónoma del Estado de México); y Emil Volek (Arizona State University, Tempe, EE.UU.).

En 2012, presentaron sus contribuciones Bernardino Bravo Lira (Universidad de Chile); Horst Pietschmann (Universität Hamburg); Allan J. Kuethe (Texas Tech University, Lubbock, Texas); Adrián Laveaga Hernández (Universidad Juárez del Estado de Durango, México).

En 2013 coparticiparon en el Seminario Antonio Sáez-Arance (Universität zu Köln) y Jiří Černík (Needmore, Pa., EE.UU.

En 2014, el Centro propició lugar para la presentación de Lilian Tintori, esposa de Leopoldo López, preso de conciencia, y de Juan Requesens, de Venezuela. En el Seminario presentaron en ese año sus ponencias también Virginia Martín Jiménez (Universidad de Valladolid); Inés Quintero y Rogelio Altez (Universidad Central de Venezuela); Emilio José Luque Azcona (Universidad de Sevilla); José Luis Belmonte Postigo (Universidad Pablo de Olavide, Sevilla); Luis Marcelo Martino y Ana María Risco (CONICET, Universidad Nacional de Tucumán); Consolación Fernández Mellén (Università degli studi Roma Tre); Antonio Sáez-Arance (Universität zu Köln); Horst Pietschmann (Universität Hamburg); y Miguel Ángel Flores (Universidad Autónoma Metropolitana, campus Azcapotzalco, Ciudad de México).

En 2015, se presentaron Ewald Meyer Monsalve (Universidad Bernardo O'Higgins, Chile), Pablo Martínez Becerra (Universidad de Playa Ancha/Universidad Adolfo Ibáñez, Chile) y Francisco Javier Cordero Morales (Universidad Tecnológica de Chile); Valerio Mendoza Guillén (FAMU, Praga); Stanislav Chládek (Michigan, Colorado, EE.UU.); Antonio Sáez-Arance (Universtät zu Köln); James Dunckerley (Queen Mary University of London); Vladimir Alexander Smith-Mesa (University College London); Laura Martínez Abarca (UNAM, México).

Fuera de los estudiantes de grado y posgrado del Centro y de sus profesores, compartieron 
las actividades también personajes ligados con la iberoamericanística del país: Pavel Frič, nieto del viajero A. V. Frič, y su esposa Yvonna, continuadores de la historia familiar en Paraguay y editores de la obra de su precursor; Bohumil Badura, investigador del Instituto de Historia de la Academia de Ciencias y antiguo colaborador del Centro, con el tema del pueblo de indios Caney en Cuba Sigfrido Vázquez Cienfuegos, en ocasión de la presentación de su libro La Junta de La Habana 1808-1810; Josef Žeňka del Instituto del Oriente Cercano y de África de la Facultad de Filosofía y Letras de la Universidad Carolina de Praga, sobre el personaje del orientalista Alois Nykl en México y EE.UU.; Jaroslav Bouček, del Ministerio de Salud de la República Checa, sobre los archivos españoles; Martin Nekola, egresado de politología de la Facultad de Filosofía y Letras de la Universidad Carolina de Praga, sobre emigración checoslovaca después de la II Guerra Mundial y, otra vez, sobre la República Dominicana y la emigración.

Todas estas conferencias y acontecimientos merecieron una gran atención e interés por parte del estudiantado y profesorado iberoamericanista, significando para el público presente un considerable enriquecimiento.

\section{Cursos de verano}

En los meses de verano de 2010 a 2015, el Centro ofreció a los estudiantes de Instituto Tecnológico y de Estudios Superiores de Monterrey en México (en adelante ITESM) un curso de verano anual (que en la última fecha ya sumó la $16^{\circ}$ edición), concebido como bloque optativo realizado en el extranjero, llamado "Valores del mundo cambiante", y que a partir de 2015 ha actualizado su concepción bajo el título "Ciudadanía y Europa del Este". El colectivo de profesores -especialistas en historia, economía, politología y medios de comunicación, literatura, música, artes plásticas y cinematografía- impartieron clases y dirigieron excursiones y visitas guiadas a sitios y eventos de interés cultural. Los estudiantes inscritos debieron aprobar las diferentes materias con trabajos escritos y exámenes orales. El mismo programa se prepara también para el año 2016. El curso corre ininterrumpidamente, caso único entre los centros de enseñanza europeos, a partir del año 2000 siendo resultado de los convenios interuniversitarios entre ITESM y la Universidad Carolina. Al inicio de la realización del curso en Praga han estado el Dr. Zidane Zeraoui (el cual también figuró varias veces como profesor acompañante) y el Prof. PhDr. Josef Opatrný (gerente del curso hasta hoy día). Pasando unos años de extraordinario aumento del interés por la Europa Central y Oriental poco conocida hasta aquel momento en México cuando se realizaban dos o hasta tres turnos del curso paralelos o consecutivos (Praga sirve de buen punto de salida para visitar los países vecinos, como Alemania, Polonia, Hungría o Austria, lo mismo que brinda oportunidades para viajar a los países de Europa del Oeste y del Sur - Inglaterra, Francia, Bélgica, los Países Bajos, o Italia y España), la situación se estableció en un curso anual. Entre los varios profesores acompañantes el "récord" se lo lleva la Dra. Luz Araceli González del Instituto de Relaciones Exteriores del campus Monterrey, con sus más de diez temporadas, la mejor conocedora de Praga y de la República Checa y, por lo tanto un gran apoyo de los estudiantes mexicanos y los profesores praguenses.

\section{Las actividades de investigación y publicación} Tanto los profesores, como los estudiantes de posgrado tomaron parte en numerosos eventos de investigación. El profesorado prosiguió trabajando en los proyectos de investigación de largo plazo: en 2011 se terminó el programa científico realizado en el marco de la Facultad de Filosofía llamado "Bases del mundo moderno reflejado en la literatura y filosofía" y apoyado por el Ministerio de Enseñanza (MSM 0021620824). A partir de 2012 se realizan en la Universidad Carolina los programas de desarrollo de áreas científicas (PRVOUK) que sirven para el apoyo institucional de la ciencia en la Universidad. Están armonizados con el Objetivo a largo plazo de la Universidad Carolina para los años 2011-2015 y representan una reacción al cambio de las condiciones del financiamiento institucional de la ciencia e investigación en la República Checa. Están financiados por los recursos que el Estado le otorga a la Universidad con el fin de apoyar un desarrollo conceptual de largo plazo de una organización dedicada a la investigación. Dentro de este marco, el Centro de Estudios Ibero-Americanos se alineó al programa PRVOUK en la subdivisión P12: Historie v interdisciplinární perspektivě (Historia en la perspectiva interdisciplinar), con el tema de "Evropa a (versus) svět: Interkontinentální a vnitrokontinentální politické, ekonomické, sociální, kulturní a intelektuální transfery a jejich důsledky" (Europa y (versus) el mundo: Transferencias políticas, económicas, 
sociales, culturales e intelectuales inter e intro continentales y sus consecuencias). En este marco han participado en numerosos simposios y entregado a la prensa varios estudios (ver más abajo bibliografía personal).

Bajo la coordinación de Josef Opatrný trabajaron los estudiantes de doctorado Michal Zourek, Lucia Majlátová y Matyáš Pelant entre 2011 y 2013 sobre un proyecto apoyado por el Ministerio de Relaciones Exteriores: "Checoslovaquia y América Latina en los años 1945-1989”. Su resultado es una publicación casi homónima Las relaciones entre Checoslovaquia y América Latina 1945-1989 en los archivos de la República checa (=Ibero-Americana Pragensia, Supplementum 38, Vydavatelství Karolinum, Praha 2015).

En 2012, Markéta Kř́̌́zová, Simona Binková y el estudiante postdoctoral del Departamento de Etnografía Ondřej Pokorný ganaron con su proyecto "Fuentes bohemicales para el estudio comparativo de la expansión colonial española en la temprana Edad Moderna" el apoyo de la Agencia Grant de la República Checa (GAČR P405/12/1242). El tema se centró en la presencia de los misioneros jesuitas originarios de la Provincia de Bohemia en Nueva España y en las islas Filipinas y Marianas y su contribución para el conocimiento recíproco entre aquellas regiones y la Europa de los siglos XVII y XVIII. La publicación saldrá en 2016 con el título Ir más allá... Fuentes bohemicales para el estudio comparativo de la expansión colonial española en la temprana Edad Moderna (=Ibero-Americana Pragensia, Supplementum 42, Vydavatelství Karolinum, Praha 2016). Participan en ella también: Pavel Zavadil (Doctor en Estudios Medievalistas Latinos y Estudios Neolatinos del Instituto de Estudios Griegos y Latinos por la Universidad Carolina de Praga). Su disertación doctoral Bohemia Jesuitica in Indiis Occidentalibus. Latinská korespondence českých jezuitů z Ameriky, Filipín a Marián v českých a moravských archivech [Bohemia Jesuitica in Indiis Occidentalibus. La correspondencia latina de los jesuitas de Bohemia desde América, las Filipinas y las Marianas en los archivos de Bohemia y Moravia], Facultad de Filosofía de la Universidad Carolina 2011, es una edición crítica de la correspondencia latina de los jesuitas de la Provincia de Bohemia activos en Ultramar. P. Zavadil está preparando una selección amplia de las cartas en traducción al checo bajo el título de Čeští jezuité objevují Nový svět. Dopisy a zprávy o plavbách, cestách a živobytí z Ameriky, Filipín a Marián (1657-1741) [Los jesuitas de Bohemia descubren el Nuevo Mundo. Cartas y relaciones sobre las navegaciones, viajes y vida diaria, de América y las islas Filipinas y Marianas (1657-1741)], Argo, Praha 2015 (con un estudio final de Simona Binková que también coparticipó en dotar la edición de un amplio aparato de notas); Pavel Fochler egresado de la Universidad Agrónoma de Praga que siempre se ha interesado por las islas Filipinas, Marianas, el Caribe y América Latina (autor de un libro de viajes a las Antillas Menores: Malé Antily. Ostrovy, piráti a plantážníci [Las Antillas Menores. Islas, piratas y terratenientes], Mladá fronta, Praha 2009, y de numerosos artículos sobre sus impresiones viajeras en la prensa checa) y Carlos Lazcano Sahagún, Licenciado en Geografía y Geología por la Universidad Nacional Autónoma de México (explorador de las zonas de Chihuahua y Baja California, reconocido espeleólogo, arqueólogo y conocedor de la prehistoria e historia de esas regiones. Fundador y actualmente Director del Museo de Historia de Baja California en Ensenada, Baja California, México. Autor de numerosos libros, varios de ellos tocantes a las misiones jesuitas y franciscanas en las zonas respectivas). Ya en mayo de 2012, el trabajo sobre este proyecto fue iniciado por los participantes y con presencia internacional con un workshop llamado Problemas y tendencias del estudio de las misiones jesuíticas honrado con su presencia y una charla introductoria de S.E. Embajador de México, José Luis Bernal.

Corrieron también proyectos de investigación ganados por los estudiantes de posgrado. Un proyecto doctoral ya del 2009, de Hana Bortlová ("Las relaciones económicas entre Cuba y Checoslovaquia en los años 60 hasta 90 del siglo XX", financiado por el Ministerio de Relaciones Exteriores de la República Checa, MZV RM 03/01/09 y dirigido por Josef Opatrný), tuvo resultado en forma de una monografía de la doctoranda Československo a Kuba v letech 1959-1962 (comp. más arriba).

Lucia Majlátová terminó el proyecto de dos años (2009-2010) con el tema de "Los contactos de Checoslovaquia y los países de América Central y la formación de la imagen mutua en la fase final de la existencia de Checoslovaquia (después de 1968)" aprovechado para llevar a cabo su disertación doctoral.

En 2010, las doctorandas V. Hingarová, S. Květinová y G. Eichlová orientadas por M. Křížová unieron sus fuerzas para llevar a cabo el proyecto 
"México. 200 años de independencia" apoyado en el programa de becas de la Facultad de Filosofía de la Universidad Carolina. El resultado homónimo del proyecto salió a la luz en checo como una obra colectiva (Vendula Hingarová - Sylvie Květinová - Gabriela Eichlová (eds.): Mexiko. 200 let nezávislosti, Pavel Mervart, Červený Kostelec 2011). M. Kř́žžová junto con Denis Belucz contribuyeron a esta publicación con "Analýza postavení katolické církve a protestantských denominací v Mexiku v 19. a 20. století a v současnosti"([Análisis de la situación de la Iglesia católica y de las denominaciones protestantes en México de los siglos XIX, XX y en la actualidad], pp. 47-67).

De 2010 a 2012 duró el proyecto de Michal Zourek "Los cambios de la percepción de Europa del Este por la sociedad argentina y chilena en el transcurso del siglo XX. Contribución para el análisis histórico de las relaciones entre Argentina, Chile y Europa oriental y para el análisis politológico del desarrollo de las izquierdas Argentina y chilena" financiado por el Departamento de Becas de la Universidad Carolina. Subvencionó una parte de su investigación doctoral y llegó a materializarse en forma de una monografía (ver más arriba).

El mismo, junto con Lucia Majlátová y Matyás Pelant y bajo la coordinación de Josef Opatrný, trabajaron entre 2011 y 2013 sobre un proyecto apoyado por el Ministerio de Relaciones Exteriores: "Checoslovaquia y América Latina en los años 1945-1989” (para la publicación ver más arriba).

Dos fueron los proyectos efectuados por los doctorandos dirigidos por Simona Binková: en 2011 a 2012, Karolina Omrtová ganó un apoyo del Departamento de Becas de la Universidad Carolina sobre "El libro de copias de Juan Alonso de Gámiz, de Olomouc, de los años 1555 a 1558. Investigación en los archivos españoles", tratándose de un tema de investigación aún vigente. El otro, en 2012, fue conseguido por Frederico Rêgo para "Reunir, analizar y traducir las cartas y documentos referentes al Padre Valentin Stansel encontrados en los archivos europeos" (una beca interna de la Facultad de Filosofía de la Universidad Carolina) que tiene que ver con su disertación preparada para la defensa.

Para los años 2013 a 2014, consiguió un apoyo en el marco del Departamento de Becas de la Universidad Carolina, para su proyecto "La competición hispano-neerlandesa en el Caribe" (No. del proyecto 540813) Eva Kubátová, doctoranda dirigida por Markéta Kř̌̌žová.
Otra estudiante de doctorado, Monika Brenišínová junto con M. Křížová lograron en 2014 el apoyo interno de la Facultad de Filosofía de la Universidad Carolina (VG FF UK 2014) con su proyecto "Historia del Arte de América Latina" (se está preparando una publicación monográfica conjunta sobre este tema para el público checo).

Monika Brenišínová tuvo éxito también en 2015 consiguiendo el apoyo interno de la Facultad de Filosofía para el proyecto "Arquitectura de la conversión y su significado en el proceso de la conquista y colonización del Nuevo Mundo". (No. del proyecto FF_VG_2015_151)

Igualmente en 2015 y de los mismos recursos fueron apoyados dos proyectos de las doctorandas Ivana Kudrnová y Lillyam Rosalba González. El primero, auspiciado por Markéta Kř́žzová con el título de "Literatura infantil latinoamericana", y el otro, entrelazado con el mismo tema, "Un manual electrónico para la enseñanza de la materia Literatura infantil latinoamericana".

Praga también fue lugar de numerosos simposios, varios de ellos internacionales. Conjuntamente el Centro Iberoamericano de la Universidad Metropolitana de Praga (Metropolitan University Prague, en adelante MUP), el Centro de Estudios Ibero-Americanos y el Instituto de Historia Mundial, los dos últimos adscritos a la Universidad Carolina de Praga, coordinaron el 30 de abril de 2010 una conferencia internacional Estado e identidad en América Central. Como responsables figuraron, respectivamente, L. Majlátová, J. Opatrný y V. Nálevka.

En el Centro de Estudios Ibero-Americanos, el 15 de octubre de 2010, J. Opatrný organizó el simposio Las relaciones checo-mexicanas (del Centro, participaron en él con sus contribuciones también S. Binková, M. Křížová y los estudiantes de posgrado). Las actas bajo la coordinación de J. Opatrný y con el mismo título se publicaron como Ibero-Americana Pragensia, Supplementum 26 (Vydavatelství Karolinum, Praha 2011). Comparte las contribuciones de J. Opatrný, "La dimensión histórica de las relaciones checo-mexicanas" (pp. 31-64); de M. Křížová "Buscar a Dios en el fin del mundo: los jesuitas de Provincia de Bohemia” (pp. 79-93) y de S. Binková “Juan, Andrés y Miguel Alemán: Buscadores de la fortuna en el México del siglo XVI" (pp. 65-77).

El 28 de mayo de 2013 él mismo y V. Hingarová coorganizaron el Simposio sobre Las relaciones checo-argentinas. Las actas homónimas 
coordinadas por J. Opatrný salieron a la luz como Ibero-Americana Pragensia, Supplementum 37 (Vydavatelství Karolinum, Praha 2014). J. Opatrný contribuyó con "El esbozo de la historia de las relaciones checo-argentinas" (pp. 11-53) y S. Binková con "Los misioneros jesuitas de Bohemia en la Provincia del Paraguay, con especial enfoque en el territorio actual argentino (Resumen de los conocimientos y líneas de investigación)" (pp. 55-72).

En los días 6 a 7 de noviembre del mismo año, Josef Opatrný organizó el simposio Historias e historiadores del Caribe hispanoparlante (los acta El Caribe hispanoparlante en las obras de sus historiadores, coord. por J. Opatrný, salieron como Ibero-Americana Pragensia, Supplementum 35, Vydavatelství Karolinum, Praha 2014). J. Opatrný, además de editor, contribuyó con "El contexto histórico de Breve historia de Cuba de Josef Polišenský” (pp. 61-70), M. Křížová participó con "Christian Georg Andreas Oldendorp y los debates acerca de la esclavitud caribeña en el siglo XVIII" (pp. 355-367), Sigfrido Vázquez Cienfuegos contribuyó con "Ejemplos del uso de la Historia en el discurso político en La Habana entre 1808 y 1814" (pp. 81-95).

El 8 de noviembre de 2013, J. Opatrný, representando el Centro de Estudios Ibero-Americanos, y K. Březinová, de MUP, coorganizaron el simposio Cold War Engagements: Czechoslovakia and Latin America 1948-1989. En este tomaron parte varios estudiantes de posgrado del Centro. Las contribuciones se publicaron en un número especial del CEJISS (Central European Journal of International and Security Studies, Metropolitan University Prague Press, vol. 7, no. 3, 2013. Ver ante todo J. Opatrný, "Czechoslovak-Latin American Relations 1945-1989: The Broather Context", pp. 12-37). Transcurrido un año, en noviembre de 2014, las dos instituciones coorganizaron un nuevo simposio llamado Borders in Latin America (coordinado por M. Křížová y K. Březinová). M. Kř́žžová es también coeditora de un número especial de la revista CEJISS (vol. 9, no. 3, 2015) donde se han publicado las contribuciones presentadas en ese evento.

En los días 4 a 5 de septiembre de 2014 , J. Opatrný organizó en el Centro el simposio Relaciones entre Europa Central y Oriental y América Latina 1945-1989. El mismo fue coordinador de sus actas Las Relaciones entre Europa Oriental y América Latina 1945-1989 (=Ibero-Americana
Pragensia, Supplementum 40, Vydavatelství Karolinum, Praha 2015). Contribuyó con "Constantas y cambios en las relaciones entre Checoslovaquia y países latinoamericanos 1945-1989" (pp. 33-68), mientras que Sigfrido Vázquez Cienfuegos participó con "Los estudios checoslovacos sobre historia de América durante la Guerra Fría” (pp. 223-236). En 2015, J. Opatrný respaldó el simposio Proyectos políticos y culturales en las realidades caribeñas de los siglos XIX y XX, con el trabajo "Domingo del Monte en la discusión sobre la trata y esclavitud", y Sigfrido Vázquez Cienfuegos con "Cuba en la historiografía checoslovaca durante la Guerra Fría".

El 10 de diciembre de 2010, M. Křížová y S. Binková organizaron en el Centro de Estudios Ibero-Americanos un coloquio El mundo en movimiento: El ámbito atlántico en la época moderna para conmemorar el 20 aniversario de la reorganización institucional del Centro en el marco de la Facultad de Filosofía de la Universidad Carolina como sujeto con carrera propia en iberoamericanística, lo mismo que para recordar el 95 aniversario de natalicio del fundador y primer director del Centro Josef Polišenský y para rendir homenaje al actual director Josef Opatrný en su 65 cumpleaños. Participaron en él los colaboradores y egresados del Centro de todas las generaciones, desde profesores actuales de la Universidad Carolina y otras universidades de la República hasta estudiantes de doctorado, con un público amplio entre el estudiantado y con la presencia de la familia Polišenský. La charla magistral la presentó Dr. Bohumil Bad'ura, en ese entonces decano de la iberoamericanística checa y colaborador del Centro desde sus inicios (fallecido en 2014: acerca de su personaje ver en otro lugar de este volumen).

Transcurridos otros cinco años, el 15 de diciembre 2015 se homenajeó en el Centro de Estudios Ibero-Americanos el Centenario de Josef Polišenský (organizado por J. Opatrný, S. Binková, M. Křížová, S. Vázquez Cienfuegos) ante un público preponderantemente estudiantil presentándose una síntesis y valoración de sus múltiples actividades, ante todo en los campos de historia de España, Hispanoamérica y las regiones lusófonas.

En marzo de 2011, M. Kř́ižová, por su parte, junto con Vlastimil Rataj y Jakub Hutera y en colaboración con la organización Cambia Perú, organizó en el Centro un evento internacional Quechua lengua nacional del Perú: Perspectivas para su preservación, uso y enseñanza en el siglo XXI. 
En mayo de 2012, en el marco del programa CEEPUS el Centro hospedó un workshop internacional Estudios iberoamericanos en la República Checa y en Hungría en el que se encontraron, presentaron sus ponencias y discutieron los estudiantes de posgrado checos con los estudiantes máster de español de la Universidad ELTE, de Budapest. Organizaron el workshop M. Křížová y S. Binková.

En octubre de 2012 el Centro de Estudios Ibero-Americanos con el apoyo de la Embajada de Brasil organizó un coloquio internacional Brasil Plural, cuyos organizadores fueron los doctorandos Matyáš Pelant y Frederico Rêgo, bajo los auspicios de S. Binková. Inauguraron el evento S.E. Embajador de Brasil George Monteiro Prata y el Director del Centro, J. Opatrný. Sus contribuciones presentaron, entre muchos, también M. Křížová y S. Binková y varios doctorandos. Además, participaron los estudiantes máster presentando posters de sus tesis recién defendidas. Las presentaciones se publicaron como una monografía colectiva Brasil Plural. I. kolokvium brazilských studií (Matyáš Pelant (ed.), Univerzita Karlova v Praze, Filozofická fakulta, Praha 2013). J. Opatrný contribuyó con "Tradice česko-brazilských vztahư"([Tradición de las relaciones checo-brasileñas], pp. 22-37); S. Binková con "Literární a výtvarný předobraz brazilského indiána $\mathrm{v}$ českých zemích v 16. a 17. stol." ([La imagen literaria y artística del indio brasileño en los países checos de los siglos XVI y XVII], pp. 56-69); M. Kř́ízová con "Odkaz otroctví a problematika 'rasy' v národním diskursu Brazílie" ([La herencia de la esclavitud y la problemática de la "raza" en el discurso nacional del Brasil], pp. 108-119).

Continuó la serie en 2013 como Brasil Plural temático (Amazonas), organizado por el Centro y la Embajada de Brasil, esta vez en la sede del Instituto Camões. La organización se debió nuevamente a los doctorandos del Centro Matyáš Pelant y Frederico Rêgo. S. Binková presentó la ponencia "As fronteiras amazônicas em discussão (séculos XVII e XVIII: a atitude dos jesuitas)".

En 2014 se celebró, otra vez con el apoyo de la Embajada de Brasil y de S.E. Embajador George Monteiro Prata, el seminario Brasil Plural con el tema As cidades brasileiras organizado por Frederico Rêgo (Centro de Estudios Ibero-Americanos e Instituto Camões), que contó con numerosa participación extranjera. Tuvo lugar en noviembre de 2014 en el Instituto de Cultura Italiana en Praga.
S. Binková habló sobre "As missões jesuitas do século XVIII como germem da urbanização". La monografía colectiva Brasil Plural. III. kolokvium brazilských studiú (Univerzita Karlova v Praze, Filozofická fakulta, Praha 2014) reúne una parte de las contribuciones presentadas.

En octubre de 2014 se celebró en Praga el $I V$ Seminario internacional. Poder y conflictividad social en América Latina preparado por Sigfrido Vázquez Cienfuegos y sus colegas españoles y auspiciado por el Centro de Estudios Ibero-Americanos y el Instituto Cervantes de Praga. S. Binková contribuyó con "Violencia en las misiones jesuíticas. Intento de una tipología (siglos XVII y XVIII)" y M. Křížová con "De guerrilleros feroces a indios miserables: Transformación de los "mosquitos" dentro del discurso colonial y postcolonial sobre la Costa de Mosquitia, siglos XVII al XIX". Junto con las demás ponencias se publicará en Ibero-Americana Pragensia, Supplementum 44.

En septiembre de 2015, M. Kř́žová tomó parte en un simposio internacional European Civilisation and the World Between Conflicts, Cooperation and Dialogue organizado por el Instituto de Historia Universal de la Facultad de Filosofía de la Universidad Carolina de Praga en el que presentó su charla sobre la imagen de América intermediada por los misioneros jesuitas. Las contribuciones de este evento se publicarán en un número especial de la revista Historie-Otázky-Problémy.

En la República Checa, pero en otras Universidades, participó S. Binková en mayo de 2012 en un simposio internacional organizado por la $\mathrm{Fa}$ cultad de Filosofía de la Universidad de Olomouc Historická Olomouc XIX dedicado a San Francisco Xavier y la cultura jesuita en los países checos. Culto, iconografía, literatura y teatro. Presentó allí el texto "San Francisco Xavier en la correspondencia y en la vida de los misioneros jesuitas de la Provincia de Bohemia" (publicado in: Štěpánek, Pavel (ed.), Svatý František Xaverský a jezuitská kultura $v$ českých zemích, Univerzita Palackého, Olomouc, 2014). Tres años más tarde fue invitada a participar en otra edición del simposio, Historická Olomouc XX, dedicado a los Silva Tarouca, nobleza de origen portugués, y a sus huellas en la cultura checa, organizado conjuntamente por el Departamento de Historia del Arte de la Facultad de Filosofía de la Universidad Palacký y por el Museo Etnográfico de Olomouc, en abril de 2015. S. Binková presentó una plática sobre "Libros y documentos portugueses de Manuel Teles 
da Silva" reflexionando sobre su relación a su país natal y sus territorios ultramarinos a través de su biblioteca y su archivo.

En abril de 2014, M. Kř́žzová dio una conferencia sobre las "Misiones en Baja California" en el Departamento de Romanística de la Facultad de Filosofía de la misma Universidad de Olomouc (dentro del programa LAST: Estudios latinoamericanos).

S. Binková es -desde su establecimiento en 2012- miembro activo de la Sociedade Checa de Língua Portuguesa que une a los profesores y estudiantes de las disciplinas ligadas con el mundo lusófono de todas las universidades de la República Checa. Participó en el $1^{\text {er }}$ coloquio (octubre de 2012 en Praga) con la presentación del interés pionero y sistemático mostrado desde los inicios del Centro de los Estudios Ibero-Americanos por el mundo luso-brasileño que se manifestó también en las páginas de su anuario Ibero-Americana Pragensia. En el $2^{\circ}$ coloquio (mayo de 2013 en Praga) habló sobre "El interés checo por el Brasil del siglo XVI en el contexto de los contactos europeos de la Unidad de los Hermanos Checos". En el $3^{\text {ero }}$ (abril de 2014 en Brno) documentó la constante atracción que hubo en los países checos por la obra apócrifa "Las cartas portuguesas de Marianna Alcoforado: traductores, editores e ilustradores checos" y en el $4^{\circ}$ (mayo de 2015 en Praga) se refirió a "Nacido en Praga (¿?), mártir en Japón (Carlo Spinola, S.J. y su reflejo en obras de origen bohemio y checo)".

La misma tomó parte en el XXXVI simposio de historia de geodesia y cartografía (Museo Nacional Técnico, Praga, noviembre de 2015) con "La contribución de los jesuitas de la Provincia de Bohemia para la representación cartográfica del Noroeste de México y Sudoeste de los EE.UU. de hoy (siglos XVII a XVIII)". La ponencia fue entregada a la imprenta.

En diciembre de 2015 se celebró en el Centro el simposio internacional Vida y obra de Juan Bosch en el contexto de la historia de la República Dominicana respaldado por Ramón Carreño, cónsul General de la República Dominicana y acompañado de la donación de un acervo importante de libros. Participaron en el evento al lado de diplomáticos dominicanos el profesorado y estudiantado checos. J. Opatrný habló de "Vida y obra de Juan Bosch en el contexto de la historia de la República Dominicana"; M. Kř́̌žová, sobre "La imagen de la isla Española en las cartas de jesuitas centroeuropeos, siglos XVII y XVIII" y Sigfrido Vázquez Cienfuegos sobre "Santo Domingo y el Caribe durante la generación de las Revoluciones Atlánticas (1789-1825)".

En cuanto a publicaciones realizadas, a parte de las monografías colectivas y las actas de simposios ya mencionadas arriba, J. Opatrný es autor de José Antonio Saco y la búsqueda de la identidad cubana (=Ibero-Americana Pragensia, Supplementum 24, Vydavatelství Karolinum, Praha 2010). Salieron a la luz también dos libros suyos dedicados a un público checo más amplio: Malá skvělá válka. Španělsko-americký konflikt, duben - červenec 1898 ([Una guerra breve y espléndida. El conflicto hispano-americano, abril hasta julio de 1898], Epocha, Praha 2013), y Pamatujte na Alamo. Od reality $k$ mýtu a zase zpátky ([Recuérdense de Alamo. De la realidad al mito y otra vez de vuelta], Epocha, Praha 2014). Participó con sus estudios también en otras publicaciones. Así, en 2010 salió su "Devatenácté století v Latinské Americe" ([El siglo XIX en América Latina], Historica Olomoucensia, Olomouc 2010, pp. 41-54); "La isla de la libertad joven de Lumír Čivrný” (in: El Caribe hispano de los siglos XIX y XX. Viajeros y testimonios, Josef Opatrný (ed.), Ibero-Americana Pragensia Supplementum 25, Praga 2010, pp. 271-282, resultado del simposio internacional llevado a cabo el año anterior); "La patria de Francisco Arango y Parreno" (in: Francisco Arango y la intervención de la Cuba azucarera, María Dolores González-Ripoll, Izaskun Álvarez (eds.), Salamanca 2010, pp. 167-177).

En 2011 se dio a la luz la monografía colectiva con el título Kolaps a regenerace: cesty civilizací a kultur: minulost, současnost a budoucnost komplexních společností ([Colapso y regeneración: caminos de civilizaciones y culturas: pasado, presente y futuro de sociedades complejas], Miroslav Bárta - Martin Kovář (eds.), Academia, Praha 2011). J. Opatrný contribuyó con el capítulo "Dlouhá cesta ke kolapsu. Konec říše, nad níž nezapadalo slunce" ([Un largo camino hacia el colapso. El ocaso del imperio sobre el cual no se ponía el sol], pp. 377-426) y M. Křŕžová con “Kolaps indiánských říší?’'([¿Un colapso de imperios indígenas en América?], pp. 345-376).

En 2011, J. Opatrný participó en el libro Paradigma kultur ([Paradigma de culturas], Aleš Čeněk, Plzeň 2011) con el capítulo "Historické předpoklady kulturní plurality v Latinské 
Americe" [Antecedentes históricos de la pluralidad cultural en América Latina, pp. 328-354]. A continuación, contribuyó al volumen de conferencias publicadas de la XXIV Escuela de verano de la Historia Dědictví materiální i dědictví ideji: XXIV. letní škola historie: Sborník přednášek ([Herencia material y herencia de ideas], Univerzita Karlova v Praze, Pedagogická fakulta, Praha 2012) con "Latinskoamerické revoluce poloviny dvacátého století" [Las revoluciones latinoamericanas de mediados del siglo XX], pp. 92-101). Asimismo, publicó los estudios "Cesta Haiti k nestabilitě” ([El camino de Haití hacia la inestabilidad], in: Historie, politika a současný život na Haiti [Historia, política y vida actual en Haití], CEVRO Institut, Praha 2012, pp. 47-56) y "Azúcar y cubanidad" (in: Fruits de la terre. Du produit exotique au symbole patriotique. Cuba $X V I I I-X X I$, Indigo \& Coté femmes éditions, Paris 2013, pp. 57-72). También participó en un volumen de homenaje al Profesor de Historia Universal de la Facultad de Filosofía de la Universidad Carolina Aleš Skřivan en ocasión de su aniversario con “Československo a Latinská Amerika 1945-1989: zvláštní př́ípad Dominikánské republiky” ([Checoslovaquia y América Latina 1945-1989: un caso especial de la República Dominicana]), in: Martin Kovář y Václav Drška (eds.), Kapitoly z obecných dějin. Panu profesorovi s láskou ([Capítulos de historia universal. Al señor profesor con amor], pp. 267-280).

Para los aficionados en historia escribió los artículos "Pamatujte na Alamo" ([Recuerden Alamo], Živá historie 1-2, Brno 2012, pp. 22-25); "Za svobodu otrokü" ([Por la libertad de los esclavos], Živá historie 4, Brno 2012, pp. 30-33); "Kubánský národní hrdina" ([El héroe nacional de Cuba], Živá historie 11, Brno 2012, pp. 3639); "Boj o stát osamělé hvězdy" ([La lucha por el Estado de una estrella aislada], Živá historie 11, Brno 2014, pp. 19-23); “Tak pravil náčelník Seatle?"([¿Así dijo el cacique Seatle?'], Živá historie 4, Brno 2014, pp. 58-62) y "Mýtus indiánských příběhů" ([El mito de las historias indias"], Živá historie 3, Praha 2015, pp. 11-13). Asimismo escribió “Občanská válka ve Španělsku” ([La guerra civil espanola], in: Plav 8, 2014, pp. 7-10).

Como resultado de trabajo de varias etapas de su vida, Bohumil Bad'ura, colaborador cercano del Centro desde su fundación, entregó a la imprenta y vio la publicación de sus Páginas de la historia del pueblo del Caney (=Ibero-Americana Pragensia,
Supplementum 30, Vydavatelství Karolinum, Praha 2013) que explora la documentación archivística sobre un pueblo de indios en Cuba oriental a través de la historia colonial hasta mediados del siglo XIX, haciendo una revisión de las aseveraciones globales de que los indígenas de las islas caribeñas desaparecieran ya en el siglo XVI.

$\mathrm{Al}$ acontecer el fallecimiento del autor, tras una grave enfermedad, J. Opatrný redactó una necrologia: "Bohumil Badura (18. 7. 1929-21. 9. 2014)" (Český časopis historický 112:4, Praha 2014, pp. 829-831).

Aparte de varias obras publicadas en el marco de diferentes simposios y congresos (ver más arriba y más abajo) M. Křížová es autora de las monografías Reyes, emprendedores, misioneros: Rivalidad imperial y sincretismo colonial en la Costa de Mosquitia, siglo XIX (=Ibero-Americana Pragensia, Supplementum 41, Vydavatelství Karolinum, Praha 2015) y Otroctví v Novém světě od 15. do 19. století ([La esclavitud en el Nuevo Mundo en los siglos XV a XIX], Nakladatelství Lidové noviny, Praha 2013).

En cuanto a estudios, salió a la luz su texto "Utopías esclavistas de América colonial"(Ibero-Americana Pragensia 42, Praha 2008, pp. 107-131). A continuación es autora de "Přelom století v hispánské Americe: Kdo jsme, odkud pocházíme, kam směřujeme?" ([La transición del siglo en Hispanoamérica: ¿Quiénes somos, de dónde procedemos y adónde nos dirigimos?], in: Anna Housková - Vladimír Svatoň (eds.), Konec a počátek: Literatura na přelomu dvou staletí, Univerzita Karlova v Praze, Filozofická fakulta, Praha 2012, pp. 163-179); "Misijní činnost obnovené Jednoty bratrské v Novém světě”([Las actividades misioneras de la renovada Unidad de Hermanos en el Nuevo Mundo], Vlastivědný sborník Novojičínska 62, Jičín 2012, pp. 35-46); "Pobřeží Moskytů jako prríklad kulturní synkreze vzešlé z kolonialismu" ([La costa de los Mosquitos como ejemplo de la síncresis cultural originada en el colonialismo], Ethnologia Actualis Slovaca 12:1, Trnava 2012, pp. 111-140); "Costa de Mosquitia: En la encrucijada de los procesos atlánticos y las ambiciones locales" (Anuario de Estudios Atlánticos 60, Las Palmas y Madrid 2013, pp. 139-173); "Misiones jesuitas y la imagen de América en Europa en los siglos XVII y XVIII" (in: Virreinatos II, Lillian von der Walde Moheno - Mariel Reinoso Ingliso (eds.), Grupo Destiempos, México, D.F. 2013, pp. 120-138); “Africké dědictví v argentinské 
společnosti a kultuře" ([La herencia africana en la sociedad y cultura argentinas"], in: Vendula Hingarová - Daniel Nemrava (eds), Argentina např́ič obory: Současné pohledy [Argentina a través de las disciplinas: Consideraciones actuales], Univerzita Palackého v Olomouci, Olomouc 2014, pp. 219-241); "Not Exactly the Other? Africans in Late Colonial and Early Independence Identity Discourse in Spanish America" (in: Přemysl Mácha - José Eloy Gómez Pellón (eds.), Masks of Identity: Representing and Performing Otherness in Latin America, Cambridge Scholars Publishing, Newcastle 2014, pp. 145-165); "Rasa" ([La raza], in: Lucie Storchová, Koncepty a dějiny: Proměny pojmů v současné historické vědě ([Conceptos e historia: Transformación de terminología en la ciencia histórica actual], Scriptorium, Praha 2014, pp. 220-229); "Střet kultur" ([Confrontación de culturas], in: Jiří Hanuš, Historická kniha mého srdce [El libro histórico de mi corazón], Centrum pro studium demokracie a kultury, Brno, 2015, pp. 39-48); y "Problem of (proto) National/Ethnic/Regional Identities of Jesuit Missionaries from Central Europe in America" (Working Paper Series of the Centre for Area Studies, No. 5, Leipzig 2015).

Para un público checo más amplio, para la serie de Breve Historia de los Estados editada por la editorial Libri, la misma es autora de una breve historia de la República Dominicana desde la época precolombina hasta la actualidad Dominikánská republika (Praha 2010), Nikaragua (Praha 2011) y Jamajka (Praha 2012).

En otra editorial, la misma publicó Mayové: Víc nežz záhady dávné civilizace ([Los mayas: Algo más que los enigmas de la Antigua civilización], Aleš Skřivan ml., Praha 2011).

Junto con S. Květinová y Z. Kostićová publicaron una monografía colectiva Krvavé rituály Střední a Jižní Ameriky ([Los rituales sangrientos de América Central y del Sur], XYZ, Praha 2011).

M. Křížová y S. Binková contribuyeron a una monografía colectiva Moderní svět v zrcadle literatury a filosofie (ed. Miroslav Petříček, Hermann \& synové, Praha 2011): la primera con el texto "Pohrdaný a potřebný, náš a jiný: Nový svět v evropském myšlení moderní doby" ([Despreciado y necesario, nuestro y otro: el Nuevo Mundo en el pensamiento europeo de la Edad Moderna], pp. 115-123) y la otra con “Takzvaná Černá legenda a její podoby $\mathrm{v}$ českém předbělohorském prostředî" ([La llamada Leyenda Negra y sus formas en los países checos en la época anterior a 1618], pp. 73-93)

En abril del año 2010 se dio el lanzamiento público de la traducción al checo de un título de la literatura medieval portuguesa, la Crónica do Rei Dom Pedro I, de Fernão Lopes (Kronika vlády D. Pedra I. Trad. de Marie Havlíková, epílogo "Kronika tří Pedrů Krutých" [La crónica de tres Pedros Crueles] de Simona Binková,pp. 109-120, Argo, Praha 2009). Coincidió con la visita oficial del Presidente de la República Portuguesa Aníbal Cavaco Silva a la República Checa y en una reunión solemne en la sede de la Rectoría de la Universidad Carolina donde pronunció un discurso dirigido a los profesores y estudiantes de la lengua portuguesa.

En 2010 salió a la luz el estudio de S. Binková "El Padre Wenceslao Linck, explorador de la Antigua California (Entre el P. Fernando Consag y Fray Junípero Serra)" (in: Carlos Lazcano Sahagún (coord.), Memoria. Homenaje a Fernando Consag. Primera Reunión de Historiadores sobre los Fundadores de la Antigua California, Sociedad de la Antigua California - Fundación Barca, Ensenada 2010, pp. 149-174), fruto de un evento internacional en Ensenada, Baja California, México, del año anterior.

S. Binková contribuyó también con varios ítems biográficos y generales acerca de los misioneros jesuitas de la Provincia de Bohemia que trabajaron en la Tarahumara en el libro de Carlos Lazcano y Dizán Vázquez, Misioneros fundadores de Chihuahua (Grupo Cementos de Chihuahua 2013, pp. 97-101, 142-147, 157-159).

La misma publicó el estudio "Kdo byl Andrés Morab Alemán? (Pokus o rekonstrukci životního př́iběhu brněnského světoběžníka 16. století)“ ([¿Quién fue Andrés Morab Alemán? Un intento de reconstruir la trayectoria de vida de un trotamundos del siglo XVI originario de Brno], in: Alena Císařová Smítková - Andrea Jelínková Milada Svobodová (eds), Libri magistri muti sunt. Pocta Jaroslavě Kašparové, Knihovna Akademie věd ČR, Praha 2013, pp. 275-285).

Para aficionados en historia fue destinado su artículo "Do Indií přes nový kontinent. Otazníky a fakta ze života Kryštofa Kolumba” [Hacia las Indias a través del nuevo continente. Dudas y hechos de la vida de Cristóbal Colón], Živá historie, mayo 2011, pp. 73-93). La misma junto con Jiří Šouša conmemoraron al primer redactor del presente anuario "Lubomír Vebr, co-fundador y redactor de Ibero-Americana Pragensia, in memoriam" 
(Ibero-Americana Pragensia 43/2009, publ. 2012).Sigfrido Vázquez Cienfuegos publicó junto a Antonio Santamaría García (del CSIC España) en 2015 "Cuba a principios del siglo XIX y su proyecto no revolucionario“, in: Rogelio Altez Manuel Chust (eds.), Las revoluciones en el largo siglo XIX latinoamericano, Madrid, Iberoamericana - Vervuert, 2015, pp. 173-194.

\section{Investigación a nivel internacional y relaciones exteriores}

Aparte de los numerosos simposios internacionales que se celebraron en Praga y sus actas publicadas (ver más arriba), Josef Opatrný desde 2009 participa en un proyecto internacional apoyado por el Ministerio de Ciencias e Innovación de España concedido al Consejo Superior de Investigaciones Científicas (HAR2009-09844).

Él mismo, participó en el simposio internacional 5 de mayo de 1862, organizado desde el 30 de abril hasta el 4 de mayo de 2012 por el Colegio de Puebla y el Estado de Puebla (México), con la contribución "Austria e intervención en México". Ésta, con el título de "Las Raíces de la política austriaca durante la Intervención francesa en México" fue publicada in: Memorias del Simposio Internacional 5 de Mayo, Puebla, El Colegio de Puebla 2013, pp. 28-61.

El mismo entre el 15 y 20 de julio 2012 participó en el 54 Congreso mundial de americanistas en Viena, organizado por la Universidad de Viena y por el Lateinamerika Institut, como miembro del comité científico y coordinador del simposio "El Caribe hispano: migraciones históricas" y autor de una de las contribuciones en ese simposio ("La búsqueda de la mano de obra para la producción del azúcar en las primeras décadas del siglo XIX en Cuba”). Igualmente Markéta Kř́ížová presentó su ponencia "Costa de Mosquitia en el contexto de la historia caribeña". Las contribuciones presentadas en esta sección del congreso se publicaron como Migraciones en el Caribe Hispano (ed. Josef Opatrný, Ibero-Americana Pragensia, Supplementum 31/2012, Univerzita Karlova v Praze, Nakladatelství Karolinum, Praha 2012 (publicado 2013), las mencionadas contribuciones en las pp. 65-79 y 149-162, respectivamente).

Josef Opatrný participó igualmente en 2012 , en los días 7 a 10 de octubre, en el simposio internacional organizado por la Universidad de los Países Vascos en Vitoria denominado Los tiempos de Espada: ciudad e ilustración, Vitoria y La
Habana con la contribución "Espada y los orígenes de la cubanidad". El texto se publicó in: Los tiempos de Espada: Victoria y La Habana en la era de las revoluciones atlánticas (Argitalpen Zerbitzua, Universidad del País Vasco, Bilbao 2014, pp. 231-251).

En 2013, en los días 10 a 11 de octubre, participó en Madrid en el simposio internacional Juego de espejos: identidad y visiones comparadas en las Antillas (siglos XVII-XX) organizado por el Instituto de Historia CSIC/Casa de Velázquez con la contribución "La cubanidad de José Antonio Saco bajo el peligro del mundo anglosajón”.

Además, fue miembro del jurado de las disertaciones doctorales de Consolación Fernández Mellén (Vitoria, 2012) y de Delphine Sappez (Universidad Jaume I, Castellón, 2013).

Markéta Kř́ižová desde 2007 hasta 2010 participó en las actividades del grupo CLIOHRES (Creating Links and Innovative Overviews for a New History Research Agenda for the Citizens of a Growing Europe), "Network of Excellence" for European History, dentro del $6^{\circ}$ programa marco de la UE. El objetivo de este proyecto era enlazar una colaboración y discusión intensas en torno a temas compartidos (no solamente) de la Historia europea. En su transcurso se han publicado treinta monografías colectivas redactadas por seis grupos de trabajo parciales, cinco monografías colectivas transversales y varias disertaciones doctorales de estudiantes incluidos en el proyecto. En este marco, en 2010, M. Kř́ížová fue coautora de la monografía colectiva Crossing Frontiers, Resisting Identities (Edizioni Plus-Pisa University Press, Pisa 2010) con sus textos"Multiple and Hybrid Identities: Inspirations for Further Research into Cultural Contact and Cultural Change" (pp. 33-55) y "Discriminating Borders and Intolerant Identities" (pp. 335-341). En el mismo año estuvo presente en la solemne sesión plenaria en Bruselas que dio por concluido el proyecto de cinco años de duración.

En abril de 2010, Markéta Křížová participó en 8th European Social Science History, conferencia internacional que se celebró en Gante. Allí tomó parte de un grupo de trabajo organizado por la Universidad de Leipzig que se dedica a la problemática de la historia de estudios de área en el contexto de la guerra fría. Posteriormente, fue invitada a formar el comité organizador del ENIUGH (European Network in Universal and Global History) en el que sigue trabajando.

En abril de 2011, M. Kř́̌žová tomó parte activa 
en la organización del Third European Congress on World and Global History que esa vez se celebró en Londres, en London School of Economics. Dirigió un panel dedicado a la historia colonial.

En enero de 2012, la misma visitó la Universidad de Leipzig. En el centro dedicado a la historia y cultura de Europa central oriental (Geisteswissenschaftliche Zentrum Geschichte und Kultur Ostmitteleuropas) dio una charla sobre los misioneros jesuitas de los países checos que actuaron en las colonias de España en América. En mayo del mismo año viajó dentro del programa Erasmus a la Universidad de La Laguna (Tenerife). Allí dio varias conferencias y consultó con los estudiantes las posibilidades de un intercambio. En el mes de julio participó junto con J. Opatrný en el 54 Congreso mundial de americanistas en Viena con una contribución (ver más arriba). En octubre del mismo año tomó parte en 3rd Bethlehem Conference on Moravian History and Music, organizado por Moravian College en Bethlehem (Pensilvania). Presentó una contribución dedicada a la problemática del estudio de las misiones cristianas desde el punto de vista del concepto de la confesionalización: "The Moravian Church and the Society of Jesus: American mission and American utopia in the age of confessionalization". Junto con las demás, ésta fue publicada en Journal of Moravian History 13: 2, pp. 197-226.

En enero de 2013, M. Křížová visitó en el marco del convenio interuniversitario la Universidad de Leipzig. En su Instituto de Romanística dio una charla sobre el tema de la reflexión de las misiones de los jesuitas de Europa central en la historiografía de los siglos XIX y XX y presidió la conferencia The Academic Making of the Orient: Russian, Central European and Transatlantic Careers. Volvió a esta universidad (Geisteswissenschaftliche Zentrum Geschichte und Kultur Ostmitteleuropas) en enero de 2015 para participar en un seminario con estudiantes dedicado a los métodos de investigación antropológicos.

En cuanto a convenios y relaciones interuniversitarias, el más duradero es el curso de verano organizado por el Centro para los estudiantes del ITESM Monterey (México). Cada año parten para estudiar en el extranjero también varios estudiantes de máster y de doctorado checos (véase más arriba).

En septiembre de 2011 fue inaugurado un programa de estudios a nivel de máster Erasmus Mundus TEMA, "European Territories (Civilisation, nation, region, city): Identity and Development", en cuya realización -aparte de la Universidad Carolina en Praga- participan Eötvös Loránd University (Hungría), École des Hautes Etudes en Sciences Sociales de Paris (Francia) y Università degli Studi di Catania (Italia). M. Kř́žžová es miembro del consorcio del programa, dirige las tesis e imparte conferencias.

S. Binková participó en octubre de 2010 en un simposio internacional Os Descobrimentos Portugueses e a Mitteleuropa organizado por la Eötvös Loránd University (ELTE) Budapest, Hungría, en colaboración con el Centro de História de AlémMar (CHAM) de Lisboa y los Institutos Camões de Budapest, Praga y Varsovia, con la contribución "O Atlas Praguense de João Teixeira Albernaz I no contexto dos Descobrimentos Portugueses". Fue publicada in: Clara Riso - István Rákóczi (org.), Os descobrimentos portugueses e a Mitteleuropa, 18-19 de Outubro, 2010, ELTE Eötvös Kiadó (Tálentum, 5), Budapeste 2012, pp. 27-38.

S. Binková coordinó la estancia de Zora Rohoušová, egresada de la Facultad de Filosofía de la Universidad Carolina de Praga y profesora de la Universidad Autónoma del Estado de México, en octubre-noviembre de 2011, organizada en conjunto por el Centro, el Instituto de Estudios Románicos y el Departamento de Relaciones Exteriores de la Facultad. Como profesora visitante pronunció en ambas instituciones educativas tres conferencias sobre temas literarios (Sor Juana Inés de la Cruz, Octavio Paz) y sobre la problemática del México prehispánico y actual. Dos de ellas fueron enviadas a imprenta.

Aparte de la participación en eventos internacionales en el extranjero (simposios, seminarios, jurados), se efectuaron también varios viajes de investigación. En Ibero-Amerikanisches Institut en Berlín y en la Biblioteca de Estado (Staatsbibliothek) investigaron en repetidas ocasiones S. Binková (finales de septiembre/principios de octubre de 2010 y febrero de 2013), M. Křížová (agosto de 2011 y marzo de 2014: en esta ocasión encabezó una excursión de estudiantes de doctorado y de máster llevándoles no solamente al IAI, sino también al Museo de Etnología en Dahlem y a la biblioteca del Instituto J.-F. Kennedy para los estudios de Norteamérica adjunto a la Universidad Libre/Freie Universität en Berlín). La misma efectuó en julio de 2013 una breve estancia de investigación también en British Library en Londres. 
En el periodo correspondiente, S. Binková realizó visitas de investigación en tres ocasiones a España: en septiembre de 2012 a Madrid (Archivo del Museo Naval y Real Academia de Historia) y a Simancas (Archivo General de Simancas). En septiembre de 2013 a Madrid (Archivo Histórico Nacional y biblioteca del Consejo Superior de Investigaciones Científicas) y en septiembre de 2014 otra vez a Madrid (Biblioteca Nacional y biblioteca del CSIC). A nivel de la República Checa realizó una breve estancia en el archivo de Jihlava (SOA Jihlava: para las matrículas de los estudiantes del Colegio jesuita de 1663-1773) y en Telč (biblioteca de la sociedad Veritas: para los textos checos antiespañoles de los siglos XVII a XIX).

En septiembre-octubre de 2015, la misma gozó de una invitación a participar en el IV Festival de la Antigua California en homenaje a Wenceslao Linck, S.J. en el 250 aniversario de la primera exploración de la Sierra de San Pedro Mártir, organizado por el Museo de Historia de Ensenada y la Sociedad de la Antigua California, y como uno de los resultados de la colaboración con la Universidad Carolina de Praga en el marco de los proyectos GAČR P405/12/1242 y PRVOUK P12 Historia en la perspectiva interdisciplinaria. Durante esa estancia, el 27 de septiembre Simona Binková y Carlos Lazcano, Director del Museo de Ensenada, dieron juntos una charla "Siguiendo los pasos de Wenceslao Linck" (Centro Cultural Riviera, Ensenada). Luego, S. Binková estrenó y comentó una exposición de fotografías de C. Lazcano "Wenceslao Linck, de Bohemia a la Antigua California" (Museo de Historia de Ensenada), referentes a la trayectoria de este jesuita checo que actuó en México. El 28 de septiembre, S. Binková dio una conferencia magistral "Wenceslao Linck, misionero y explorador de la California" (CEARTE, Ensenada) y el 30 de septiembre, la misma presentó el tema de "La expulsión de los jesuitas de Baja California (y de Nueva España)" (CEARTE, Ensenada).

En los días siguientes se realizaron las charlas y encuentros: en San Quintín, Baja California (con los profesores de historia del municipio de Ensenada); en Bahía de los Ángeles (con los especialistas del medio ambiente y etnólogos de la zona); y en Guerrero Negro (con los pobladores actuales de las antiguas misiones jesuitas de San Francisco de Borja Adac y Santa Gertrudis, y con sus descendientes y parientes). En este último lugar se homenajeó al Señor Don Eugenio "Queno" Ceseña Urías, a quien le tocó a atender la misión de Santa
Gertrudis en $7^{\mathrm{a}}$ u $8^{\mathrm{a}}$ generación y finado trágicamente en 2010. S. Binková recordó su memoria en la conferencia "Un californio en la tierra de Wenceslao Linck" y junto con C. Lazcano presentaron el tema de "Wenceslao Linck en California".

En Ensenada, el Presidente Municipal Gilberto Hirata Chico entregó a S. Binková el reconocimiento de "Visitante Distinguido" y la llave de la ciudad por su contribución a la propagación del conocimiento de la historia de Baja California.

S. Binková aprovechó la estancia en México para reanudar su investigación de hacía años en México, D.F. (Archivo Nacional de México y Archivo Histórico de la Provincia Mexicana de la Compañía de Jesús) para continuar el proyecto corriente.

S. Vázquez Cienfuegos en una estancia de investigación realizada en Sevilla entre diciembre de 2013 y enero de 2014 para visitar el Archivo General de Indias, aprovechó para realizar la presentación de su libro La Junta de La Habana en la Escuela de Estudios Hispano-Americanos (CSIC). Fue invitado a la Universidad de Panonia en Veszprém (Hungría) en marzo de 2014 donde impartió la conferencia "Party in Havana. One day in life of the creole elite in the early 19th Century". En abril del mismo año fue invitado a la Universidad de Colonia donde impartió las conferencias "La Junta de La Habana: adaptación del pacto colonial", "La esclavitud a ojos de los habaneros del siglo XIX" y "Perspectivas sobre historia y etnografía en la América Colonial".

En diciembre de 2014 durante una estancia en la Universidad de Extremadura organizó en Cáceres el Seminario en torno a la caída del Muro de Berlín, donde participó con la ponencia "La historiografía iberoamericanista checoslovaca: una revisión 25 años después de la Revolución de Terciopelo".

Desde 2014 es investigador de la MUP donde ha colaborado en la organización del evento celebrado en octubre de 2015 Cultural Cold War Eastern European Propaganda in Latin America con la ponencia "Historians and protagonists. Studies on Latin America in Czechoslovakia during the Cold War".

Desde 2014 también pertenece al grupo de investigación País Vasco y América: Vínculos y relaciones atlánticas, de la Universidad del País Vasco como investigador externo.

Fruto de esta colaboración ha realizado visitas de investigación al País Vasco y Sevilla en primavera y otoño de 2015. 
A nivel de máster se prosiguió el intercambio de estudiantes en el marco del programa Erasmus (Universidad de La Laguna y otras universidades de España), lo mismo que en forma de convenios interuniversitarios (ITESM México, más recientemente Argentina). Algunos estudiantes -ante todo a nivel de posgrado- optaron por su propia elección de la Universidad receptora (Perú, Chile, Brasil y otros), buscando fondos de apoyo institucionales y particulares.

\section{Otro tipo de actividades}

En el lapso respectivo se llevaron a cabo varias excursiones con los estudiantes, no solamente al extranjero (Berlín, ver más arriba), sino también en la República Checa, con el fin de acercarles archivos, bibliotecas y otros lugares que puedan tener relación con su carrera de estudio. Tras las primeras experiencias y por iniciativa de los estudiantes de varios niveles, el momento decisivo fue el establecimiento de "Iberoklub" (iberoklub@seznam.cz) en 2012 que reúne a los estudiantes, doctorandos, egresados y profesores de iberoamericanística.

El 7 de enero de 2012 se realizó un workshop en el Museo de Brasil en Ralsko (organización de Petr Polakovič) con el tema de Brasil. Participaron en él desde estudiantes de máster con presentaciones de sus tesis hasta doctorandos y el profesorado (S. Binková), con la presencia del ex-cónsul general en São Paulo y luego encargado de los asuntos de los compatriotas en el extranjero por el Ministerio de Relaciones Exteriores, Stanislav Kázecký.

En mayo de 2012, ya en el marco de Iberoklub establecido, se llevó a cabo una excursión a Bohemia del Oeste, organizada por Petr Polakovič y Monika Brenišínová, orientada a las relaciones entre Brasil, la América española y los países checos. Bajo la tutoría de S. Binková y con presencia de M. Křížová los participantes visitaron el castillo de Kynžvart (el canciller Metternich y las relaciones con el Brasil), las ciudades de Jáchymov (extracción de plata en el siglo XVI, la acuñación de los táleros que se divulgarían como pesos, reales de a ocho, posteriormente dólares), los balnearios de Mariánské Lázně y Karlovy Vary (éste visitado por el Emperador de Brasil Pedro II y su cónyuge) y Nejdek (lugar de nacimiento del jesuita W. Linck que actuó en Baja California). Otra excursión de este tipo (febrero de 2014, con participación de S. Binková y Pavel Štěpánek, profesor de Historia del Arte de la Universidad Palacký en Olomouc) fue dirigida a Bohemia del Este y las partes adyacentes de Moravia: se visitaron las ciudades de Chrudim (archivo regional, la emigración), Chotěboř (palacio de los Dobřenský, emparentados con el heredero del título monárquico del Brasil), Ždaár nad Sázavou (ex-convento cisterciense - la exposición del arte barroco, y la capilla de San Juan Nepomuceno en Zelená Hora), Velké Meziříčí (castillo y museo, retrato de A. Stierkanovský/Strzanovský, ex-misionero en México). Ambos eventos fueron organizados por P. Polakovič junto con Monika Brenišínová y contaron con un workshop de estudiantes y profesores.

S. Binková, en colaboración con la Embajada de España en la República Checa y el Instituto Cervantes de Praga, formó parte del jurado de la Ruta Quetzal BBVV (destinado ante todo para los estudiantes de los institutos bilingües en la República Checa), desde por lo menos 2007 hasta 2013, la última edición abierta a los países de todo el mundo.

M. Křížová colaboró con la Universidad Carolina y con la Facultad de Filosofía en los eventos destinados a presentar el ambiente académico a alumnos de escuelas secundarias y de institutos.

S. Vázquez Cienfuegos, en muchas ocasiones junto a J. Opatrný, ha colaborado habitualmente con el Instituto Cervantes de Praga, por ejemplo en la organización de las I Jornadas sobre hispanismo, edición y cultura digital, junto a la Universidad de Bohemia del Sur (České Budějovice), moderando la Mesa redonda "José Martí en Europa" convocada por la Embajada de Cuba en Praga en enero de 2014, o la presentación de diferentes libros de la colección Iberomericana Pragensia Supplementum en 2014 y 2015.

Se efectuaron igualmente variadas actividades para un gran público:

En octubre de 2010 fue inaugurada en Viena, en la sala de exposiciones de Novomatic Forum, la exposición "1000 Jahre Inca Gold” cuya curadora fue Markéta Křížová. En los años 2009 a 2010, esta exposición se había celebrado en Praga y en Brno.

J. Opatrný y S. Binková colaboraron en el guión de la exposición del Museo Náprstek en el marco del Museo Nacional de Praga denominado La época de los descubrimientos marítimos (noviembre de 2013 - septiembre de 2014).

S. Binková asesoró la preparación del guión de un video sobre las misiones jesuitas de la Antigua California (dir.: Sergio Gabriel Raczko, 
Argentina), lo mismo que dos series del programa Šumné stopy (Huellas bellas) referentes a los lazos de los países checos con Argentina y con Brasil (guión: David Vávra), transmitidos por los canales televisivos ČT 2 y ČT art. Para la radio participó junto con Šárka Grauová en el programa Telefonotéka (ČRo Vltava - moderadora Blanka Stárková, junio de 2015) con ocasión del Día de Portugal y de Luís de Camões, con el tema de las navegaciones marítimas. S. Binková tradujo, asimismo para un gran público checo, 100 divů Latinské Ameriky. Historie, kultura a př́rodní krásy Jižní a Střední Ameriky a Karibiku ([100 maravillas de América Latina. Historia, cultura y bellezas naturales de América del Sur, la Central y del Caribe], REBO Productions, Praha 2010; trad. del original alemán 100 schönsten Plätze Südamerikas, editor Manfred
Leier, Dörfler Verlag, Eggolsheim 2007). Es una publicación que presenta tanto en texto, como en fotografías los sitios de Latinoamérica inscritos en el Patrimonio de la Humanidad de la UNESCO.

M. Křížová junto con el astrofísico Jiří Grygar fueron invitados al programa Hyde Park Civilizace (canal de televisión ČT24, diciembre de 2012) para comentar el nacimiento y los derrumbes de las grandes civilizaciones y la visión apocalíptica según el calendario maya.

J. Opatrný es un diligente comentarista de la situación política actual en los países latinoamericanos (Argentina, Venezuela, Cuba, Brasil y otros) para los medios de comunicación checos.

por Simona Binková (Praga) (Escrito en español por la autora) 